\title{
SELEÇÃO E USOS DOS LIVROS DIDÁTICOS DE HISTÓRIA PARA OS ANOS INICIAIS DO ENSINO FUNDAMENTAL:
}

\author{
ALGUMAS QUESTÕES A PARTIR DO OLHAR DE DUAS \\ PROFESSORAS
}

\begin{abstract}
SELECTION AND USE OF HISTORY TEXTBOOKS FOR ELEMENTARY SCHOOL: ISSUES FROM THE POINT OF VIEW OF TWO TEACHERS
\end{abstract}

\author{
Cristiani Bereta da Silva ${ }^{1}$ \\ David de Souza João
}

\begin{abstract}
RESUMO: A presente discussão constitui recorte de pesquisa mais abrangente desenvolvida no mestrado do Programa de Pós-Graduação em Educação da UDESC, que investiga as escolhas, representações e usos dos livros didáticos de História de duas professoras que atuam nos $4^{\circ}$ e $5^{\circ}$ anos do Ensino Fundamental, em escolas públicas estaduais de Laguna/SC. Neste artigo o objetivo é discutir as relações estabelecidas entre as prescrições e avaliações do Estado relativas ao livro didático e as expectativas e representações construídas e reelaboradas pelas professoras, a partir de suas experiências no decorrer do processo de escolha dos livros, no PNLD de 2013. As análises apoiam-se principalmente em entrevistas orais realizadas com duas professoras, nomeadas na pesquisa de Joana e Maria. Neste trabalho, que se utiliza da metodologia da história oral, as fontes orais são compreendidas como possibilidades narrativas portadoras de significados, sujeitas a elaborações subjetivas, versões e interpretações feitas de lembranças, simulações, esquecimentos e ocultações. O interesse principal recai na singularidade com que essas professoras utilizam o livro didático de História e sobre como as políticas públicas voltadas ao livro e ao ensino de História ressoam em seu cotidiano de trabalho e aparecem reelaboradas em suas narrativas.
\end{abstract}

Palavras-chave: Livro didático de História. Anos iniciais. Ensino de História.

\begin{abstract}
This discussion is currently integrating part of a broader MA research project developed at Programa de Pós-Graduação em Educação, UDESC, which investigates the choices, representations, and uses of History textbooks by two Elementary School teachers in public state schools in the city of Laguna, Santa Catarina, Southern Brazil. In this article the objective is to discuss the relations established between the Federal prescriptions and evaluations towards the History

\footnotetext{
${ }^{1}$ Professora Titular do Departamento de História, Centro de Ciências Humanas e da Educação, UDESC. Bolsista Produtividade em Pesquisa do CNPq. E-mail: cristianibereta@gmail.com.

${ }^{2}$ Licenciado em História (UNISUL). Mestre em Educação (PPGE-UDESC). Professor da Rede Estadual de Santa Catarina. E-mail: historianaescola@hotmail.com.
} 
textbooks, and the representations and expectations constructed and elaborated by the teachers, based on their experiences in the process of choosing the textbooks in PNLD/2013. Analyses are mainly based on oral interviews performed with two elementary school teachers, named Joan and Mary in order to maintain their anonymity. In this paper, which uses the methodology of oral history, oral sources are seen as narrative possibilities embedded with meaning, subjective elaborations, and subject to versions and interpretations permeated with recall, simulation, oblivion, and forgetfulness. The main interest falls on the unique manner in which these teachers use the History textbook, and how public policies on History teaching and textbooks resonate on their everyday work, appearing with new elaboration in their narratives.

Keywords: History textbooks. Elementary School. Teaching History.

\section{Considerações iniciais}

Em "História dos livros e das edições didáticas: sobre o estado da arte", publicado no Brasil em 2004, Alain Choppin afirma que, após ser negligenciado nos estudos da história da educação, o livro didático passaria a ser objeto de interesse dos historiadores na década de 1960, adquirindo notável impulso nas pesquisas internacionais a partir da década de 1980 . O estado da arte realizado por ele identificou a existência de duas grandes categorias de pesquisa que se sobressairiam entre as demais: aquela que concebe o livro didático como um documento histórico igual a qualquer outro e centrava as análises nos conteúdos, e aquela que considera o livro didático como um objeto físico, um produto fabricado, comercializado, distribuído ou, ainda, como um objeto concebido em razão de certos usos, consumido e avaliado em um determinado contexto (CHOPPIN, 2004, p. 554). Outra importante questão levantada pelo autor em sua análise reside na constatação de que apenas na década de 1990 os usos e a recepção dos livros didáticos passariam a ganhar atenção dos pesquisadores. As investigações advindas desse interesse atentam para questões relativas ao consumo do livro, aos tipos de leitura, às escolhas, às liberdades em relação à organização curricular proposta e à efetiva influência exercida pelo livro no comportamento das crianças e da sociedade em geral (CHOPPIN, 2004, p. 564).

Os pesquisadores brasileiros acompanharam a tendência internacional no que respeita o interesse pelos livros didáticos, tal como 
apontada por Alain Choppin (2004). Kazumi Munakata (2012) observa a forte expansão de publicações sobre o tema entre as décadas de 1990 e 2010. Nos anos 1970 a 1980, por exemplo, não passavam de 50 títulos, entre 1993 e 2000 o número aumentou para 265 trabalhos e entre 2001 e 2011 chegou-se a surpreendente marca de 800 trabalhos. O boom dessa produção passaria a apresentar, no conjunto de temas e abordagens, deslocamentos e renovações importantes, ultrapassando as preocupações observadas nas pesquisas dos anos 1980, que se dedicaram a encontrar nos livros didáticos "a presença insidiosa da mentira, da manipulação, do preconceito, da mistificação, da legitimação da dominação e da exploração burguesas - em suma, da ideologia" (MUNAKATA, 2005, p. 271). O reconhecimento das múltiplas dimensões constitutivas do livro didático, como sua materialidade, a diversidade de sujeitos envolvidos em sua produção, circulação, usos e práticas etc., sua inserção na escola, sua faceta como mercadoria, cuja produção e consumo são regulados pelo Estado, passaram a ser objeto das pesquisas sobre os livros didáticos.

Com recorte temporal próximo daquele privilegiado por Kazumi Munakata (2012), Circe Bittencourt (2011) realizou outro balanço, dessa vez considerando especificamente o livro didático de História. Com base em levantamento de 121 teses e dissertações defendidas entre 1980 e 2009, a pesquisadora observa que a maioria das pesquisas foi desenvolvida na área de Educação e em cursos de mestrado. Também destaca as mudanças de abordagem em relação ao livro, nesse período. Se na década de 1980 eram mais comuns estudos que denunciavam o caráter ideológico dos livros didáticos de História, na década de 1990 os enfoques foram mais diversos "em torno de temáticas tais como formação de professores, currículos, linguagens e ensino de História, história do ensino de História, produção historiográfica e livro didático" (BITTENCOURT, 2011, p. 500). Na primeira década do século XXI, ganhariam força estudos que, além da variedade temática e de abordagens, renovaram perspectivas de análises, indicando "um maior compromisso em entender o livro didático com base em fundamentação teórica abrangente, com diálogos com autores de outras 
áreas pertinentes" capazes de evidenciar as especificidades das obras escolares (BITTENCOURT, 2011, p. 509).

A partir de então observa-se que a crítica em relação aos conteúdos, ou de lacunas deles, de denúncias etc. passaria a dar lugar a investigações sobre condições de elaboração dos livros, sua materialidade, seu caráter multidimensional, políticas públicas de avaliação, escolha por parte dos docentes etc. Circe Bittencourt (2011) observa também que houve maior preocupação com os usos dos livros didáticos de História nas pesquisas realizadas na primeira década do século XXI, o que corresponderia a uma mudança na perspectiva de análise e a uma concepção mais ampliada e complexa do livro escolar. Contudo, mesmo a despeito da consolidação do campo de pesquisa, acompanhado de renovação temática e de análise, Munakata (2012, p. 192) observa que os usos desses livros por professores e estudantes permanecem como questão crucial, pois "afinal, como são efetivamente utilizados os livros didáticos na sala de aula por professores e alunos?", e indica que haveria ainda a necessidade de se desenvolver uma metodologia de pesquisa capaz de dar suporte a tal investigação. Em outro levantamento sobre pesquisas relacionadas ao livro didático de História, Flávia Caimi (2013) indica que questões sobre abordagens metodológicas; as especificidades da cognição histórica e mesmo estudos comparados entre livros nacionais e estrangeiros estariam entre os temas que ainda careceriam de maior atenção por parte dos pesquisadores da área. Deve-se ressaltar ainda que do levantamento realizado por essa pesquisadora, apenas 5 dissertações abordaram os usos dos livros e nenhuma tese de doutorado, o que também informa que há ainda muito espaço para pesquisas que lancem novos olhares sobre o livro didático, especialmente no que se refere aos seus usos por parte de professores e estudantes.

Muito embora constitua-se em estudo de caso, a pesquisa desenvolvida no âmbito do mestrado (JOÃO, 2014), e a qual esse artigo é recorte, configura-se em esforço de contribuição ao campo, considerando-se que tanto o ensino de História nos anos iniciais quanto os usos e apropriações dos livros didáticos pelos docentes quando ensinam História 
nesse nível, são ainda pouco tematizados. Para a construção desse trabalho foram realizadas observações de aulas e entrevistas orais com duas professoras que atuam nos $4^{\circ}$ e $5^{\circ}$ anos do Ensino Fundamental, ao longo do ano letivo de 2013. Também foram feitas análises dos livros usados em sala por elas e outros materiais de uso cotidiano, como cadernos, por exemplo. A investigação explorou aspectos do livro didático e o compreendeu tanto como fonte e objeto da pesquisa histórica quanto como produto cultural comercializável, consumível e que, dependendo das condições, do lugar e do tempo, pode ter funções e usos bem diversificados (BITTENCOURT, 2011). O estudo mencionado centrou-se nas relações entre a prática docente e o uso do livro no que se refere ao ensino de História, propriamente.

Para esse artigo, como já indicado, procedeu-se a um recorte, privilegiando o processo de escolha do livro didático de História que envolveu as duas professoras, sujeitos da pesquisa, no ano de 2013. Pretende-se discutir as relações que elas estabeleceram com o Guia do Livro Didático de 2013, do Programa Nacional do Livro Didático (PNLD) e com as expectativas e representações construídas sobre o ensino de História nos anos iniciais. Não constitui interesse, portanto, problematizar os conteúdos dos livros escolhidos, mas sim aspectos que fazem parte do processo de escolha desses livros e seus usos nas escolas estudadas. Questões referentes ao Guia do Livro Didático de História, de 2013, alvo do processo de escolha assinalado pelas professoras nas entrevistas, e aos livros didáticos escolhidos e utilizados por elas serão articuladas, em alguma medida na discussão, mas não serão alvo de análise propriamente.

Neste artigo as análises apoiam-se principalmente em entrevistas orais realizadas com elas, chamadas aqui de Maria e Joana ${ }^{3}$. Maria trabalha no $4^{\circ}$ ano da EEB Comendador Rocha e Joana no 5ํa ano da EEB Jerônimo Coelho, em Laguna/SC. Maria tem 45 anos, é casada, católica e possui um filho. Possui formação em magistério no nível médio e em Artes como curso

\footnotetext{
${ }^{3}$ Muito embora as professoras tenham autorizado o uso das entrevistas, assinando termo de consentimento livre e esclarecido, optou-se por proteger suas identidades nomeando-as pelos nomes fictícios de Maria e de Joana.
}

História \& Ensino, Londrina, v. 25, n. 1, p. 509-528, jan./jun. 2019 
superior. Ela é efetiva no quadro da rede pública estadual e atua no magistério há mais de 25 anos - desde 1985 atua apenas nos anos iniciais. Geralmente ela trabalha com turmas do $4^{\circ}$ e do $5^{\circ}$ ano, e no ano letivo de 2013 foi responsável pelo $4^{\circ}$ ano/02 e $4^{\circ}$ ano/03 da escola. Joana tem 38 anos, é casada, católica e possui uma filha. Possui formação em Pedagogia desde o ano de 2000, trabalha como professora admitida em caráter temporário (ACT) e atua no magistério há pouco mais de 10 anos. Geralmente trabalha com turmas do $4^{\circ}$ e do $5^{\circ}$ ano, e no ano letivo de 2013 foi responsável pelo $5^{\circ}$ ano/01 e $5^{\circ}$ ano/02 da escola.

As entrevistas foram analisadas considerando-se as reconstruções que as professoras elaboraram sobre sua própria prática em sala de aula: dimensões sobre o ensino de História nos anos iniciais articuladas aos usos do livro didático. Convém ressaltar que se parte da premissa de que as narrativas orais são sempre atualizadas no presente, portanto lidam-se aqui com dimensões que exigem perspectivas diferentes: a História como uma produção discursiva (ou seja, a escrita de uma história a partir de narrativas orais) e como representações sobre determinados acontecimentos passados, com memórias pessoais e também memórias coletivas. Assume-se aqui a postura de não tomar as fontes orais como evidências factuais, depositários de informações ou meros recursos para completar lacunas que outras fontes não preenchem, mas sim como narrativas portadoras de significados, sujeitas a elaborações subjetivas, versões e interpretações feitas de lembranças, simulações, esquecimentos e ocultações. Procedimento metodológico, portanto, em que se constroem fontes, interpelando sujeitos, induzindo e estimulando narrativas (ALBERTI, 2006; DELGADO, 2006; PORTELLI, 1997).

\section{A seleção dos livros e seus usos no cotidiano escolar}

A partir da década de 1990 o crescimento de pesquisas sobre livros didáticos no Brasil também parece vincular-se à atuação das políticas públicas educacionais na avaliação, compra e distribuição de livros didáticos 
no país, conforme apontado por Circe Bittencourt (2011) e Flavia Caimi (2017). Foi ainda no Estado Novo que pela primeira vez se estabeleceu uma política pública voltada para o livro didático, com a criação da Comissão Nacional de Livros Didáticos, em 1938, cujas atribuições envolviam o estabelecimento de regras para a produção, compra e utilização desses livros. Na década de 1960, sob o governo ditatorial militar, houve também políticas específicas relacionadas à compra e distribuição de livros didáticos. Mas o marco significativo dessas políticas públicas foi a criação, em 1985, do PNLD, sob a responsabilidade da Fundação de Assistência ao Estudante (FAE) e vinculado ao Ministério da Educação (MEC). O objetivo era o de adquirir e distribuir de modo universal e gratuito livros didáticos para toda a rede pública de Ensino Fundamental. Porém, na prática, a universalização da distribuição do livro didático passou a acontecer gradativamente a partir de 1995, contemplando-se inicialmente as disciplinas de Língua Portuguesa e Matemática para os anos finais do Ensino Fundamental. Em 1996 se iniciaria efetivamente a avaliação pedagógica dos livros didáticos, no qual passou-se a exigir que "a aquisição de obras didáticas com verbas públicas para distribuição em território nacional estaria sujeita à inscrição e avaliação prévias, segundo regras estipuladas em edital próprio" (MIRANDA; LUCA, 2004, p. 125). Em 1997, com a extinção da FAE, o PNLD foi assumido pelo Fundo Nacional de Desenvolvimento da Educação (FNDE), que aumentou a eficiência e a abrangência do Programa. Desde então foram sendo incluídas no programa diferentes disciplinas escolares (a disciplina de História foi incluída em 1997) e os professores passaram a tomar parte no processo de escolha dos livros. Cabe destacar que a avaliação dos livros didáticos foi marcada desde sempre por "tensões, críticas e confrontos de interesses" (MIRANDA; LUCA, 2004, p. 127) dos diferentes sujeitos coletivos e individuais envolvidos no processo.

Após a avaliação realizada no âmbito do PNLD são publicados guias de livros didáticos para cada área de conhecimento que faz parte do rol de disciplinas escolares. Nos guias constam as resenhas das coleções aprovadas, os critérios de avaliação e o parecer sobre eles. A função dos 
guias é subsidiar as escolhas das coleções pelos professores. ${ }^{4} \mathrm{~A}$ avaliação e escolha dos livros didáticos acontecem todos os anos, intercalando os anos iniciais do Ensino Fundamental, os anos finais do Ensino Fundamental e o Ensino Médio. O Guia de Livros Didáticos - PNLD 2013 destina-se aos anos iniciais do Ensino Fundamental. Esse guia, o processo decisório de escolha dos livros e suas referências aos livros didáticos e as aulas de História são elementos que compõem as lembranças das professoras em suas narrativas. Para os anos iniciais as professoras possuíam a tarefa de escolher uma coleção de livro didático de História destinado aos $2^{\circ}, 3^{\circ}$, $4^{\circ}$, e $5^{\circ}$ anos e ainda escolher um livro de História Regional destinado ao $4^{\circ}$ ou $5^{\circ}$ anos. O processo de seleção dos livros didáticos nas escolas públicas já faz parte da cultura escolar contemporânea e ainda é pouco estudado no conjunto das pesquisas relativas aos usos dos livros didáticos por professores.

Quanto à relação que emerge no processo de escolha dos livros didáticos, as professoras relatam:

Antes da escolha do livro didático geralmente chega para nós aqui na escola um representante, um folhetim, exemplares de livros, ou até mesmo através de site e e-mails de vendedores os livros que foram aprovados pelo PNLD e pelo governo. Sempre que dá procuro ficar de olho nas coleções, nos conteúdos, nas imagens e nas atividades. Como eu gosto de História, sempre paro para dar uma olhadinha a mais nessa área, meio que faço já minha escolha individual. No dia mesmo da escolha, a escola nos libera. Vamos até a Gerência Estadual de Educação ${ }^{5}$ e nos reunimos; aí tem professores da maioria das escolas estaduais - Laguna, Imbituba, Imaruí, Paulo Lopes -, enfim, das escolas da nossa regional. Discutimos, trocamos figurinhas e fizemos nossas escolhas. (Maria, 2013).

A escolha do livro didático é uma coisa que já vem quase definida na escola. A orientadora ou a diretora diz quais os livros que vão estar à disposição para a escolha dos professores. A gente dá uma olhada por cima, olha mais os textos e atividades e escolhe. O que mais me preocupa são

\footnotetext{
${ }^{4}$ Atualmente o processo de escolha dos livros pelos professores ocorre apenas no Portal do FNDE e não mais nas escolas. Cada professor tem uma senha gerada para acessar o portal e realizar a seleção da coleção com a qual espera trabalhar.

${ }^{5}$ A 19 a Gerência Regional de Educação (GERED) é o setor responsável pela educação pública estadual do grupo de seis municípios, com sede em Laguna: Laguna, Imbituba, Imaruí, Garopaba, Paulo Lopes e no recém-emancipado município de Pescaria Brava.
} 
os livros de Português e de Matemática. No dia da escolha, vamos a uma reunião na GERED. Lá tem um monte de professoras, cada uma faz suas escolhas, às vezes a maioria vence, ou senão cada escola faz sua escolha em particular, e assim os livros são escolhidos. Às vezes, quando chego nas escolas os livros já foram escolhidos, mas ultimamente tenho participado do processo de escolha dos livros didáticos. (Joana, 2013).

A percepção sobre o processo da escolha é marcada pelos lugares sociais ocupados por essas professoras: Maria é efetiva e Joana é professora admitida em caráter temporário. Esses lugares sociais distintos, no que respeita a configuração do regime de trabalho, parece também incidir no exercício do ofício na escola e ajudam a compreender a inserção de cada uma na escolha dos livros, bem como suas impressões. Maria se coloca como um sujeito autorizado, com voz ativa nas decisões sobre quais seriam as melhores obras didáticas, enquanto Joana relata que às vezes os livros já estão escolhidos quando chega à escola. A professora Maria afirma sua simpatia pela área de História, o que a faz observar as coleções didáticas da área com mais atenção. Isso talvez se deva à sua formação na área de Artes. É possível perceber que Maria sente a importância em participar do processo de escolha do livro didático. Ela considera esse momento crucial para a tentativa da "boa escolha", que, se bem-sucedida em sua utilização, vai contribuir para a qualidade de suas aulas e sua segurança na condição de professora. Por outro lado, Joana parece não se ver ocupando lugar decisivo nesse mesmo processo como docente. Sua fala acompanha o teor das queixas de outros docentes da rede estadual catarinense no que se refere aos ACTs: é frequente que não consigam participar das decisões e também que não sejam informados de como ocorreram as discussões que subsidiaram as decisões tomadas pela direção e pelos outros professores.

Joana tem uma posição bem demarcada quanto à escolha do livro didático. Em sua experiência ela analisa a relação do profissional com o trabalho docente e as necessidades do aluno (faixa etária, nível de compreensão etc.), bem como a formação dos autores. A professora 
lamenta que pessoas com pouca experiência profissional em relação à docência decidam sobre uma ferramenta que deveria ser de atribuição do professor, cuja opinião em muitos casos chega a ser ignorada:

Como já mencionei em outro momento, acho esta escolha um pouco complicada, pois às vezes é feita por pessoas que não estão na sala de aula, por uma professora que não trabalha mais na escola, ou nossa opinião não é escutada. Mas, quando participo, penso que deve ser feita através de um consenso entre as equipes e os professores. Procuro identificar as minhas necessidades e dos alunos, da minha clientela que vai trabalhar desse ponto de partida. O livro deve fornecer atualidades, boa grafia, ilustração e não aquele textão, a linguagem clara e próxima do nosso entendimento e dos alunos, isso é o mais difícil a meu ver, principalmente os livros da tua área [História], fácil compreensão da faixa etária dos alunos, e que devem ser feitos por editoras importantes e conhecidas, assim como autores de renome e de vasta especialização em suas áreas. [...] Em relação a isso, penso que o que é bom não deve ser descartado; às vezes ficamos presos às inovações que na teoria são maravilhosas, mas quando chega na hora da prática não funcionam. Um livro didático me faz escolhê-lo quando percebo uma linguagem clara, eficiente e feita para crianças e suas professoras. Se a coleção anterior estiver dentro desses padrões, não tenho por que não escolhê-la novamente. Também vou com uns macetes que adquirimos ao longo do tempo: autores, coleções e editoras boas são sempre as mesmas. (Joana, 2013).

Procuro escolher os livros didáticos que já são frequentes nas outras disciplinas. Por exemplo: autores já bem conhecidos da História, da Geografia, das Ciências e da Matemática. Isso também vale para editoras; escolher boas editoras também pode ser o caminho para o acerto. E, por último, penso, caso a coleção do ano anterior esteja obtendo sucesso, prefiro continuar com a mesma coleção, mas, claro, atualizada e com uma nova roupagem. Enfim, mais atualizada. (Maria, 2013).

Sobre a prática docente e as diversas possibilidades de utilização dos livros didáticos nas aulas, as professoras relataram:

Procuro ter o livro didático de história como um parceiro nas aulas, como uma ferramenta, pois não é sempre que tenho um mestre nesta área para enriquecer as minhas aulas. Quando dou aula de História, procuro fazer com que os alunos viagem no tempo e no espaço comigo. Leio o texto, peço que leiam o texto, copiem o que acho que é importante, analisamos as imagens e resolvemos os probleminhas de cada capítulo. Trabalho aquilo que o plano de curso nos 
obriga a trabalhar, mas sempre tomando o livro didático como ponto de partida e de chegada. (Maria, 2013).

Tu não vai ficar com essa de dizer se sou tradicional ou não [risos]. Vou ser bem sincera: como não sou professora de História e não tive bons professores de História, não que eu lembre [se mostra pensativa] dou minhas aulas de história só em cima dos livros didáticos, o que eles dizem é lei [diz enfaticamente]. As aulas são planejadas mensalmente através dos livros; entrego meu planejamento, recebo o ok e vou trabalhar em cima daquilo que planejei. Os textos que passo no quadro são do livro; a leitura é do livro; atividade é a que o livro tem. As provas, faço 5 perguntas do assunto que trabalhamos, todas essas, tiro do livro didático de História. Se são bons ou ruins eu não sei, não sou formada em História, mas, se foi escolhido para estar nas escolas, só repasso os que eles dizem. (Joana, 2013).

Sobre a relação cotidiana das professoras com os livros, nota-se alguma diferença de posicionamento entre elas. Enquanto Maria indica em sua fala que vê o livro didático como "parceiro" e lida com ele como "uma ferramenta", Joana o vê como um "plano" ou "roteiro" a ser seguido. Conforme suas palavras, ela "dá aulas em cima do livro". Por mais que Maria ainda o tenha como ponto de partida e de chegada, faz questão de demarcar que não se prende a ele, mas dele tira aquilo que classifica de melhor como auxílio para suas aulas, a fim de que consiga "viajar" com seus alunos.

Por sua vez, Joana tem no livro o portador da verdade, parece o compreender como uma prescrição legal do que deve ser ensinado, sem discutir se existem outras versões ou não de um determinado assunto, não se posicionado nesse sentido, mesmo quando questionada. Ela atribui a tarefa de escolha totalmente à escola, justificando sua atitude pelo fato de não ser habilitada na disciplina. Daí considerar o livro um manual a ser seguido.

Ainda em relação aos usos na sala de aula, as professoras falaram:

Às vezes até consigo tirar deles um comentário mais crítico, principalmente de charges e dos pequenos trechos dos textos box explicativos. Trabalho bastante com charge; eu gosto da irreverência e eles também, mas confesso que somente nos assuntos que eu domino mais isso ocorre, principalmente os livros didáticos de História regional. (Maria, 2013). 
É difícil extrair deles algo mais crítico, pois muitos estão sendo alfabetizados no $5^{\circ}$ ano, pra você ver; alguns ainda não sabem nem ler nem escrever; dessa forma, mal conseguem entender a ideia principal do texto, daí ter um censo crítico, piora a situação. Pra ser bem franca, não me preocupo com a criticidade dos alunos; nesse momento minha missão é alfabetizá-los. (Joana, 2013).

Nas falas acima pode-se apreender a importância atribuída à formação de um pensamento crítico, bastante enfatizado nos documentos da área, a exemplo dos Parâmetros Curriculares Nacionais - História para o Ensino Fundamental. O professor toma para si a responsabilidade de ser um mediador, aquele que incita questionamentos e contribui para o desenvolvimento da criticidade dos alunos. E à História é dada a relevância de se trabalhar essas questões. Na opinião de Maria, por exemplo:

A disciplina de História nos anos iniciais, para a escola, percebo não ser considerada uma disciplina muito importante, pois muitos profissionais acham que somente as disciplinas de Português e Matemática são determinantes no processo de alfabetização. Contudo, a minha humilde opinião é bastante clara nesse assunto. Considero todas as disciplinas importantes, pois todas elas colaboram no processo de alfabetização, por realizarem diferentes formas de leitura, interpretação, e por desenvolverem a linguagem e a formação do indivíduo de forma ampla e participativa. Percebo que através da disciplina de História podemos provocar no aluno momentos de reflexão capazes de levá-lo à compreensão de conceitos de forma crítica, com um poder de criticidade maior, dessa forma extraindo deles ideias de cunho construtivo e transformador. (Maria, 2013).

Quando do momento de observação das aulas, percebeu-se que as aulas de Joana estavam mais voltadas para o ensino da leitura e dos cálculos; de certa forma, confirmavam aquilo que Maria falou no trecho acima: valorização dos saberes escolares relativos as áreas de Português e de Matemática. Ela assim justifica sua opção:

Eu inicio a semana com as aulas de Português e Matemática, eles estão mais descansados, mais "light". No meio da semana eles têm Ciências, Artes e Educação Física, quando chega o final de semana, História e Geografia. Eles já passaram a semana toda aqui, tiveram as aulas de Português e Matemática, então penso que para o fim de semana tem que ser as disciplinas mais tranquilas. (Joana, 2013).

História \& Ensino, Londrina, v. 25, n. 1, p. 509-528, jan./jun. 2019 
A concentração dos saberes relacionados a Matemática e ao Português nos anos iniciais é prática naturalizada, haja vista a força da tradição que hipoteca aos docentes dos primeiros anos escolares a responsabilidade de ensinar as crianças a dominar a escrita, a leitura e as operações matemáticas básicas. Contudo, sabe-se que a criança tem seu primeiro contato com o saber histórico escolar também nesses anos. Selva Guimarães Fonseca (2009, p. 6) lembra que mesmo não sendo reconhecido por muitos "os professores e os alunos nos primeiros anos de escolarização aprendem, ensinam, fazem história. [...] A História é uma disciplina essencialmente formativa!".

São questões relativas ao mais próximo como, por exemplo, as representações do local, as que primeiramente se colocam no ensino de História nos anos iniciais. Também questões relacionadas a percepções temporais e outros conhecimentos influenciados pela cultura histórica e que ultrapassa a conformação das disciplinas escolares ou mesmo a construção da matriz disciplina da História como área de conhecimento nesse nível de ensino. A produção, os usos e as funções do conhecimento histórico são social e politicamente demarcados, incidindo em fronteiras entre sujeitos, saberes, tempos e espaços que se entrelaçam, se produzem e se reproduzem na urdidura histórica (FONSECA, 2009) e marcam presença nas salas de aula, independentemente do nível de ensino.

As duas professoras disseram não possuir referenciais teóricos para ensinar História e, em suas falas, apontam para uma maior preocupação com os conteúdos de Língua Portuguesa e de Matemática. Faz-se importante notar que outras pesquisas já chamam a atenção para essa questão relativa à formação (SCHATZMANN, 2010). Claro está que as professoras não são especialistas, recebem uma formação humanística geral e seu maior desafio reside em articular diferentes saberes no processo de alfabetização e letramento das crianças. Elas não são formadas em História, mas certamente possuem suas percepções e saberes sobre essa área de conhecimento, construídas ao longo de suas vidas e carreiras. Seus saberes constituídos pela experiência (TARDIF; LESSARD; LAHAYE, 1991) 
fazem-se presentes no cotidiano da sala de aula e elas ensinam História mesmo quando pensam não ensinar. O desafio é pensar o lugar da história como saber escolar nessa etapa da escolarização e sua efetiva contribuição no processo de ensino e aprendizagem e de alfabetização.

Atentar para as escolhas, os usos e as relações estabelecidas entre os professores e professoras e os livros didáticos adquire ainda maior relevância quando se trata dos anos iniciais do Ensino Fundamental. Concorda-se aqui com a importância de se ensinar História nos anos iniciais, na sua contribuição para o desenvolvimento de habilidades de busca do conhecimento do mundo pela criança (OTTO, 2009). Muitas das representações construídas nos primeiros anos de escolarização vão perdurar até a vida adulta.

Na GERED de Laguna, o livro escolhido para os anos iniciais nas duas escolas pesquisadas foi "Projeto Descobrir História", de autoria de Heloisa Amaral Dias Oliveira e Glaucimara da Silva Baraldi, do Grupo Saraiva. Em relação à História Regional, apenas Maria o utiliza regularmente - trata-se do livro "Estudando a história de Santa Catarina", de Cyntia Simioni França, publicado pela editora Moderna.

A proposta pedagógica do livro "Projeto Descobrir História" foi assim avaliada:

Os livros exploram diferentes fontes e recursos, utilizados em variadas situações de ensino-aprendizagem, como certidão de nascimento, quadro informativo, linha do tempo, site, árvore genealógica, entrevista, poema, notícia de jornal, cantiga de roda, depoimento e/ou relato, legislação, documento histórico, calendário, texto acadêmico, cordel, tabela, obra de arte, música, cartaz, gráfico, entre outros. No entanto, observam-se limitações na utilização dos mapas. Na elaboração das atividades, nota-se que elas se tornam mais complexas e exigem diferentes habilidades na medida em que os volumes avançam. A pertinência de algumas atividades e exercícios deve ser avaliada pelos docentes com atenção, para que se verifique se não extrapolam o tamanho e a complexidade adequados à faixa etária que será atendida (BRASIL, 2012, p. 151).

E o livro "Estudando a história de Santa Catarina":

Os objetivos de um ensino de História baseado na problematização são observados apenas, em parte, nos 
textos e atividades. Há proposição de atividades e trabalho com fontes que podem permitir aos alunos a construção de habilidades cognitivas diversas, com destaque para a interpretação e a memorização. As competências de análise, investigação, generalização, argumentação e síntese são trabalhadas de forma mais incidental nas seções Historiando e Aprofundando o conhecimento. (BRASIL, 2012, p. 203).

Pode-se se afirmar que ambos os livros selecionados receberam avaliações positivas expostas no Guia de Livros Didáticos, mas com considerações que solicitam a atenção do professor para determinados aspectos relativos a pertinência de algumas atividades ou a distribuição pouca equilibrada entre textos e atividades no que respeita a problematização do conhecimento histórico. Quando perguntadas sobre o Guia as falas de ambas as professoras foram genéricas não identificando no documento aspectos que sustentaram suas respectivas escolhas. A questão central parece residir na relação estabelecida com o próprio livro que aciona gostos pessoais e hábitos relativos ao uso após alguns anos. Nas reuniões nas escolas e na GERED de Laguna, as professoras concordam em seguir usando o mesmo livro a qual já estão acostumadas. Tal postura indica que a coleção escolhida preenche os requisitos valorizados por elas: livros os quais já conhecem, de uma editora conhecida, com autores conhecidos. Destaca-se que a relação que as professoras entrevistadas mantem com o Guia do Livro Didático se aproxima da posição de outros professores, haja vista que alguns estudos indicam a pouca expressividade do Guia nos processos de decisórios, "uma vez que seleção das obras pelos professores é feita pelo exame dos livros fornecidos pela editora in loco, o que acaba por conferir vantagem para as grandes empresas, que dispõem de recursos para enviar os livros antecipadamente às escolas" (CAIMI, 2017, p. 47).

Joana informou que não usa livro de História Regional em suas turmas, apenas os livros didáticos de História destinados aos $4^{\circ}$ e $5^{\circ}$ anos. Novamente ela chama a atenção de que não fez parte do processo de escolha também do livro de História Regional. Mesmo não tendo realizado a escolha propriamente, uma das aulas ministradas pela professora Joana teve como tema a invasão espanhola na Ilha de Santa Catarina, com a 
utilização do livro "Santa Catarina de todas as gentes: História e Cultura" (FIORI; LUNARDON, 2009).

Diferentemente de Joana, Maria escolheu um livro didático de História do Brasil e um exemplar de História Regional de acordo com o que ela classifica como o melhor. Ela diz que no início de 2013 utilizou mais o livro "nacional" do que o regional, mas sempre que possível tenta conduzir os assuntos da sala de aula para a realidade de seus alunos. Nesse sentido, ela explica: "É uma tentativa minha, não que eu seja obrigada pela orientação da escola; acho difícil até para as colegas que possuem essa consciência. Já te disse, sou fascinada pela História." (Maria, 2013). Pode-se notar que a professora e a escola estão dentro dos parâmetros do processo de escolha sugerido pelo MEC. A professora fez sua escolha no tempo solicitado, apresentou suas ideias e, com o seu aval, selecionou textos que refletissem o âmbito nacional e o regional. Contudo, embora haja diferenças importantes nas falas de uma e outra professora, há que se considerar que ambas construíram seus próprios repertórios e roteiros de usos dos livros didáticos, bem como formas de se relacionar e atribuir importância e significado ao ensino de História nos anos iniciais. E essas relações sempre guardarão boa dose de aproximação e distanciamento com as prescrições legais relativas aos livros didáticos e ao ensino de História.

\section{Algumas considerações finais}

Em suas diferenças ambas as professoras parecem apontar para a relativa independência no processo de escolha do livro didático, nas escolas. Contudo, suas falas também informam que tais escolhas dependem da posição social dos sujeitos e do poder de negociação que possuem entre seus pares, bem como do conhecimento e argumentação sobre cada área de conhecimento. A professora Maria exalta todo o ritual de escolha de que ela participa, desde o início na sua escola até o encontro com professoras de outras escolas; lamenta, contudo, que o diretor não queira mais ceder um dia de trabalho para esse ritual. Em nenhum momento ela se refere ao 
guia do PNLD especificamente. Enfatiza que para ela o segredo é escolher o melhor em cada disciplina, e esse melhor passa pela opinião de todas as colegas presentes e pela uniformidade nas coleções. Muitas vezes voltam seus olhares para as obras que mais constam na biblioteca da escola, os autores mais conhecidos, as maiores editoras, e não necessariamente para aquelas obras que possuem linguagem mais inovadora ou que trazem textos e atividades mais criativos.

Já a professora Joana trata da complexidade do processo de escolha para aqueles que trabalham em caráter temporário, pois lidam também com a rotatividade de vagas entre as escolas e por isso em algumas ocasiões têm sua opinião ignorada. A leitura e o entendimento desse processo passam pela forma "peculiar" com que as orientações do guia do PNLD são recebidas nas escolas. Embora ambas as professoras admitam que buscam seguir as orientações do Guia ou do MEC, elas praticamente não os citam em suas falas. Por fim, em sua fala, a professora Joana explica o que entende por livro ideal: ele precisa estar atento às demandas colocadas pelos professores e alunos, pois eles são os consumidores finais.

Em suas diferenças, as professoras Maria e Joana informam a centralidade do livro didático em suas práticas cotidianas. A professora Maria vai além, enfatiza em sua entrevista que o considera um material rico e maravilhoso. Para ela, a importância que se deve dar aos livros didáticos não tem fronteiras, limites geográficos, pois são capazes de oportunizar viagens, de dar a conhecer lugares. A professora Joana o define como importante transmissor de conhecimento, um veículo, uma fonte de saber científico. O livro didático aparece como portador de verdades sobre o conteúdo a ensinar. Em sua concepção e realidade de trabalho foi por meio dos livros que os conceitos abstratos se tornaram reais para o momento de ensino e aprendizagem da História.

Nessa teia de posicionamentos, as professoras expõem suas posturas no uso dos livros em suas aulas e na forma como percebem o ensino de História nos anos iniciais. No que diz respeito às aulas, uma delas, a professora Joana fez questão de enfatizar que era habilitada em Pedagogia,

História \& Ensino, Londrina, v. 25, n. 1, p. 509-528, jan./jun. 2019 
não era professora de História; quanto aos seus tempos de aluna, lembra inclusive de não ter tido bons professores dessa disciplina. Planeja suas aulas de História e até mesmo as provas, com base nos textos e nas atividades que o livro didático utilizado prescreve. Por último, faz um alerta: se as aulas foram boas ou ruins, ela não sabe julgar, mas utilizou os livros para que fossem boas aulas.

Ambas, desde o "chão da escola", fazem apropriações particulares sobre os livros, sobre as aulas de História. As duas professoras não fizeram referências a problemas dos livros didáticos usados, como por exemplo, a "ideologia subjacente a sua abordagem de conteúdos", ou as lacunas de determinados temas etc. Parecem desconhecer - ou se conhecem não atribuíram significado - às críticas sofridas pelos livros didáticos nas pesquisas desenvolvidas nas últimas décadas. Relataram dificuldades de ensinar História nos anos iniciais em razão de suas respectivas formações e atribuíram ao livro didático função irredutível ao atendimento desse desafio. Em que pese suas dificuldades reconhecem e defendem a importância do ensino de História para formação de um pensamento crítico já nos anos iniciais evidenciando que há muito ainda a se estudar sobre o que se ensina e o que se aprende de História nesse nível de ensino.

\section{Referências}

ALBERTI, Verena. Fontes orais: história dentro da História. In: PINSKY, Carla Bassanezi (org.). Fontes Históricas. 2. ed. São Paulo: Contexto, 2006. p. $155-234$.

BITTENCOURT, Circe Maria Fernandes. Produção didática de História: trajetórias de pesquisas. Revista de História, São Paulo, n. 164, p. 487-516, jan./jun. 2011. Disponível em:

http://www.revistas.usp.br/revhistoria/article/view/19206. Acesso: 3 set. 2015.

BRASIL. Guia de livros didáticos: PNLD 2013. História. Ensino fundamental anos iniciais. Brasília: Ministério da Educação, Secretaria de Educação Básica, 2012.

CAIMI, Flávia Heloisa. O que sabemos (e o que não sabemos) sobre o livro didático de história: estado do conhecimento, tendência e perspectivas. In: GALZERANI, Maria Carolina Bovério; BUENO, João Batista Gonçalves e 
JUNIOR, Arnaldo Pinto (org.). Paisagens da Pesquisa Contemporânea sobre o livro didático de História. Campinas: Centro de Memória/Unicamp, 2013. p.35-52.

CAIMI, Flávia Heloisa. O livro didático de história e suas imperfeições: repercussões do PNLD após 20 anos. In: ROCHA, Helenice; REZNIK, Luis; MAGALHÃES, Marcelo de Souza (org.). Livros didáticos de história: entre políticas e narrativas. Rio de Janeiro: FGV, 2017. p.33-54.

CHOPPIN, Alain. História dos livros e das edições didáticas: sobre o estado da arte. Revista Educação e pesquisa. São Paulo, v. 30, n. 3, p. 549-566, set/dez. 2004. Disponível em: http://www.scielo.br/scielo.php?pid=S151797022004000300012\&script=sci_arttext. Acesso: 29 mai. 2015.

DELGADO, Lucilia de Almeida Neves. História oral: memória, tempo, identidades. Belo Horizonte, Autêntica, 2006.

FIORI, Almeida Neide; LUNARDON, Regina, Ivone. Santa Catarina de todas as gentes: História e Cultura: $4^{\circ}$ ou $5^{\circ}$ ano de História: PNLD 2010/2012. Curitiba, 2009.

FONSECA, Selva Guimarães. Fazer e ensinar história. Belo Horizonte: Dimensão, 2009.

JOÃO, David de Souza. Duas professoras e o ensino de História nos anos iniciais do ensino fundamental em Laguna/SC. 2014. Dissertação (Mestrado em Educação) -Florianópolis: UDESC, 2014.

MIRANDA, Sonia Regina; LUCA, Tania Regina de. O livro didático de história hoje: um panorama a partir do PNLD. Revista Brasileira de História, v. 24, n. 48, p. 124-144, 2004. Disponível em:

http://www.scielo.br/scielo.php?script=sci_arttext\&pid=S0102-

01882004000200006. Acesso: 29 mai. 2015.

MUNAKATA, Kazumi. Histórias que os livros didáticos contam, depois que acabou a ditadura no Brasil. In: FREITAS, Marcos Cezar de (org.).

Historiografia brasileira em perspectiva. 6. ed. São Paulo: Contexto, 2005. p. 271-296.

MUNAKATA, Kazumi. O livro didático: alguns temas de pesquisa. Revista Brasileira de História da Educação, v. 12, n. 3 [30], p. 179-197, set./dez. 2012. Disponível em:

http://www.periodicos.uem.br/ojs/index.php/rbhe/article/view/38817.

Acesso: 3 set. 2015 .

OTTO, Clarícia. O ensino de história nos primeiros anos de escolarização: produzir e mediar conhecimentos. In: CARVALHO, Diana Carvalho;

LATERMAN, Ilana; GUIMARÃES, Leandro Belinaso; BORTOLOTTO, Nelita. 
Relações interinstitucionais na formação de professores. Araraquara: Junqueira \& Marin: Florianópolis: FAPEU, 2009. p. 167-185.

PORTELLI, Alessandro. O que faz a história oral diferente. Projeto História: Revista do Programa de Estudos Pós-Graduados em História e do

Departamento de História da PUC/SP, São Paulo, n. 14, p. 25-39, fev. 1997.

SCHATZMANN, Marilane. Artes de viver, artes de aprender: o ensino de história na trajetória de duas professoras de anos iniciais. 2010. Dissertação (Mestrado em Educação) - Universidade Federal de Santa Catarina, Centro de Ciências da Educação, Programa de Pós-Graduação em Educação, Florianópolis, 2010.

TARDIF, Maurice; LESSARD, Claude; LAHAYE, Louise. Os professores face ao saber: esboço de uma problemática do saber docente. Teoria \& Educação. Porto Alegre: Pannonica, n. 4, p. 215-233, 1991.

\section{Entrevistas:}

Professora Maria. Entrevista concedida em Laguna em 29 de julho de 2013. Professora Joana. Entrevista concedida em Laguna em 30 de julho de 2013. 